\title{
The Chemical Composition of the Cell Walls of Penicillium digitatum Sacc. and Penicillium italicum Whem.
}

\author{
By V. GRISARO, N. SHARON AND RIVKA BARKAI-GOLAN \\ Department of Biophysics, The Weizmann Institute of Science, and \\ Division of Fruit and Vegetable Storage, The Volcani Institute of \\ Agricultural Research, Rehovoth, Israel
}

(Accepted for publication 27 September 1967)

SUMMARY

Purified cell walls were isolated from hyphae of Penicillium digitatum Sacc. and $P$. italicum Whem. Electron micrographs showed microfibrils in the walls. The walls are composed chiefly of carbohydrate material, mainly D-glucose, together with D-galactose, glucosamine and mannose. Only small amounts of protein were found. Fractionation with alkali and acid indicated that the walls contain several glycans.

\section{INTRODUCTION}

The composition, structure and biosynthesis of fungal cell walls have been investigated only to a limited extent (Aronson, 1965). It is known that the chemical and physical structure of these walls is complex, and that they are composed mainly of carbohydrate material, in the form of polymers of glucose, galactose, mannose and glucosamine (the latter as chitin) (Aronson, I965; Sharon, 1965), but the various polymeric components have been isolated from the walls and characterized in a few cases only. The walls of two species of the genus Penicillium have been studied. Crook \& Johnston (I962) analysed qualitatively the wall of Penicillium notatum and found glucose to be the major component; small amounts of galactose, glucosamine and mannose were also found. With walls of $P$. chrysogenum, Hamilton \& Knight (I962) found mannose, galactose, glucosamine, glucose, xylose and rhamnose in the approximate molar ratios of $I: 3: 4 \cdot 5: 9: 0 \cdot 5: 0 \cdot 5$. Fractionation with alkali and acid indicated that these walls had at least two chemically distinct polysaccharide layers.

Penicillium digitatum and $P$. italicum are the main pathogenic fungi which cause serious spoilage to stored citrus fruit in Israel, and improved methods for the control of these fungi are required. Since several antibacterial substances, notably penicillin, kill bacteria by specifically inhibiting cell-wall biosynthesis (Martin, I966), it might be possible to develop antifungal agents which act in a similar way. For this purpose, a detailed knowledge of the chemical structure and biosynthesis of fungal walls may be necessary; as a first step we have examined the chemical composition of the walls of $P$. digitatum and $P$. italicum.

\section{METHODS}

Culture conditions. Spores of Penicillium digitatum Sacc. and of P. italicum Whem. were collected from Io-day single-spore cultures on potato glucose agar incubated at $25^{\circ}$. Spore suspensions in distilled water $\left(10^{6} \mathrm{spores} / \mathrm{ml}\right.$.) were used as inocula. Fern- 
bach bottles containing $250 \mathrm{ml}$. potato glucose broth were inoculated with $2 \mathrm{ml}$. of spore suspension. After $20 \mathrm{hr}$ of incubation at $25^{\circ}$ the hyphae were harvested by filtration through cheesecloth and washed four times with cold distilled water. To get sufficient quantities of hyphae, 30 bottles were inoculated with $P$. digitatum spores and 6 bottles with those of $P$. italicum. The same culture media and techniques were used for growth of $P$. chrysogenum.

Preparation of cell walls. In a typical experiment, $\mathrm{I} \cdot 2 \mathrm{~g}$. of vacuum-dried Penicillium digitatum hyphae, I5 g. glass beads (Minnesota Mining and Manuf. Co., Type I30-5005) and $50 \mathrm{ml}$. water were stirred at top speed in a Servall Omnimixer cooled in an icewater bath (Hamilton \& Knight, 1962; Sharon \& Jeanloz, 1964) for I hr. Disintegration was complete since no whole cells could be observed in samples examined under the microscope $(\times 1200)$. The mixture was then centrifuged in a Clay Adams Safeguard centrifuge at low speed $(80 \mathrm{~g})$ for $5 \mathrm{~min}$. and the precipitate (glass beads and intact cells) discarded. The supernatant fluid was centrifuged in the same centrifuge at high speed $(800 \mathrm{~g})$ for $20 \mathrm{~min}$. The precipitate was suspended in water $(24 \mathrm{ml}$.) and washed by differential centrifugation, first at low speed and then at high speed. Washing was repeated ten times; in the last few washes, no precipitate formed at low-speed centrifugation, and the supernatant fluid did not absorb at $260 \mathrm{~m} \mu$. The washed cell walls were then freeze-dried, yielding $213 \mathrm{mg}$. of a slightly grey fluffy material ( $18 \%$ of the dry weight of hyphae used). $P$. italicum gave a similar yield.

Before freeze-drying, the walls were examined with the electron microscope. Electron micrographs were taken with an RCA EMU-2A electron microscope. Specimens were prepared on Formvar and carbon-coated grids. Shadow casting was with $\mathrm{Pt}$ at an angle of $\mathrm{I}: 4$.

Fractionation of cell-wall components. The procedure used was based on the work of Hamilton \& Knight (1962). Lipids were removed from the cell walls (200 mg.) by extraction with ether $(50 \mathrm{ml}$.) for $2 \mathrm{hr}$ in a Soxhlet extractor. The ether-extracted walls were dried in air at room temperature, suspended in $\mathrm{N}-\mathrm{NaOH}$ ( $10 \mathrm{ml}$.) and the suspension stirred for $3 \mathrm{hr}$ at room temperature. The walls were removed by centrifugation, and extracted again with alkali as before. The alkali extracts were pooled, ethanol $(96 \%, v / v$, in water, $40 \mathrm{ml}$.) was added, and the mixture allowed to stand overnight at $2-4^{\circ}$. The precipitate which formed was collected by centrifugation, washed with ethanol $(96 \%, \mathrm{v} / \mathrm{v}$, in water) in the centrifuge until neutral, and dried in vacuum over $\mathrm{KOH}$ and $\mathrm{CaCl}_{2}$.

The residue which remained after alkali extraction was washed with water in the centrifuge until neutral, dried in vacuum, suspended in $\mathrm{H}_{2} \mathrm{SO}_{4}(72 \%, \mathrm{v} / \mathrm{v}$, conc. $\mathrm{H}_{2} \mathrm{SO}_{4}$ in water, $\mathrm{I} \mathrm{ml}$.) and the suspension allowed to stand at room temperature for $48 \mathrm{hr}$. The insoluble residue was collected by centrifugation and washed with water till neutral; the first water wash ( $12 \mathrm{ml}$.) was added to the $72 \% \mathrm{H}_{2} \mathrm{SO}_{4}$ extract. The combined extract was diluted to give a final concentration of $\mathrm{N}_{-} \mathrm{H}_{2} \mathrm{SO}_{4}$, and heated at $100^{\circ}$ or $6 \mathrm{hr}$. The hydrolysis mixture was neutralized with solid $\mathrm{BaCO}_{3}$, the precipitate removed by filtration and washed with a small volume of boiling water. The combined filtrates were freeze-dried.

For analysis of sugars, the ether-extracted walls and the various cell fractions were also hydrolysed as above $\left(\mathrm{N}-\mathrm{H}_{2} \mathrm{SO}_{4}, 6 \mathrm{hr}, 100^{\circ}\right)$ and neutralized in the same way.

Nitrogen was estimated by the procedure of Dumas (Steyermark, 196I) and phosphorus by the method of King (1932). Ash was estimated in samples which were oxi- 
dized with fuming $\mathrm{HNO}_{3}$ and then heated at $600^{\circ}$ to constant weight. Neutral sugar was determined by the phenol method of Dubois et al. (1956), and reducing sugar by the method of Park \& Johnson (1949), with glucose as standard.

Acid hydrolysates were analysed qualitatively by descending paper chromatography on Whatman No. I paper with the following solvent systems: (a) $n$-butanol + acetic acid + water $(25+6+25$ by vol.; upper phase); (b) isoamyl alcohol + pyridine + water $(3+3+0.9$ by vol.); (c) $n$-butanol + ethanol + water $(4+\mathrm{I}+\mathrm{I}$ by vol.); $(d) n$-butanol + pyridine + water $(6+4+3$ by vol.). Chromatograms were run for $18 \mathrm{hr}$. Reducing compounds were detected by the silver nitrate reagent (Sharon \& Jeanloz, 1960) and amino sugars and amino acids by ninhydrin ( $0.5 \%$ in acetone). The nature of the various sugars present was inferred from experiments with appropriate authentic compounds as markers, and in the case of glucose and galactose this was substantiated by enzymic experiments (see below).

Glucosamine was estimated by the colorimetric Elson-Morgan method as modified by Gardell (I953) with D-glucosamine hydrochloride (Pfanstiehl) as standard. In some of the experiments, the glucosamine was separated from the neutral sugars with the aid of Dowex 50 (Boas, 1953). It was further identified by ion-exchange chromatography on the Beckman-Spinco amino acid analyser (Spackman, Stein \& Moore, 1958). D-Glucose and D-galactose were estimated enzymically by the glucose oxidase (Glucostat) and galactose oxidase (Galactostat) reagents (Worthington Biochemical Corporation, Freehold, New Jersey), respectively. Amino acids were determined on the Beckman-Spinco amino acid analyser after samples had been hydrolysed for $20 \mathrm{hr}$ in $6 \mathrm{~N}-\mathrm{HCl}$ at $100^{\circ}$ in sealed ampoules (Spackman et al. 1958).

\section{RESULTS}

The electron micrographs of the walls (Pl. I, fig. I, 2) indicate that they are rodshaped, in accord with the typical morphology of hyphae of Penicillium digitatum and P. italicum. They exhibit a micro-fibrillar structure (cf. Aronson, 1965) which can clearly be seen in the internal part of the wall (Pl. I, fig. 2). No distinct fibrillar structure was seen on the external surface of the walls. The gross structure of the wall and the fibrils was not affected by prolonged treatment with alkali $(\mathrm{N}-\mathrm{NaOH}$, $6 \mathrm{hr}$, room temperature).

The walls of both organisms were composed mainly of carbohydrates. Glucose, galactose, mannose and glucosamine were identified by paper chromatography of acid hydrolysates of cell walls; trace amounts of rhamnose and xylose were also present. Quantitative analysis showed (Table I) that the major sugar was D-glucose, which comprised about one half of the weight of the walls. The other neutral sugars, D-galactose and mannose, accounted together for $12-14 \%$ of the weight. The proportions of these sugars, as well as those of glucosamine, did not differ markedly in the two organisms analysed. The main difference was in the quantity of ash. Whereas no ash was found in the walls of Penicillium italicum, the ash content of the walls of $P$. digitatum was consistently very high. A small part of this ash was accounted for by the presence of phosphate, but we have no explanation for the source of the bulk of the ash. It was not an artifact of the experimental procedure used, since no ash was found in the walls of $P$. italicum. Furthermore, we did not find any ash in walls of $P$. chrysogenum which we prepared. 
The protein content of the walls appeared to be rather low, as could be inferred from the percentage of non-amino sugar nitrogen (total $\mathrm{N}$ minus amino sugar $\mathrm{N}$ ) in the walls. This figure was $0.82 \%$ for Penicillium digitatum and $0.20 \%$ for $P$. italicum; using the factor $6 \cdot 25$, this corresponds to $5 \cdot I \%$ and $I \cdot 25 \%$ protein in the walls of the two organisms, respectively. Analysis of acid hydrolysates $\left(20 \mathrm{hr}, 6 \mathrm{~N}-\mathrm{HCl}, 100^{\circ}\right)$ of the walls on the amino acid analyser showed the presence of the typical protein amino acids, which amounted to $3 \%$ of the weight of the walls of $P$. digitatum and to $\mathrm{I} \cdot 5 \%$ of those of $P$. italicum. A comparison of our results with those of Hamilton \& Knight (I962) for walls of $P$. chrysogenum shows that, qualitatively, the composition of the walls of the three Penicillium species is similar. There were, however, some quantitative differences, notably in glucose, which was lower in $P$. chrysogenum, and in the content of galactose and glucosamine, which was significantly higher (up to 3 times) in the walls of this organism than in those of $P$. digitatum and $P$. italicum.

\section{Table I. Analyses of freeze-dried cell walls of Penicillium digitatum and $P$. italicum after lipid extraction}

Total reducing sugar, $\mathrm{D}$-glucose, $\mathrm{D}$-galactose and glucosamine were estimated in the walls after hydrolysis $\left(\mathrm{N}-\mathrm{H}_{2} \mathrm{SO}_{4}, 6 \mathrm{hr}, 100^{\circ}\right)$ and neutralization of the hydrolysate with $\mathrm{BaCO}_{3}$.

$\begin{array}{lcc} & \begin{array}{c}P . \text { digitatum } \\ \%(\mathrm{w} / \mathrm{v})\end{array} & \begin{array}{c}P . \text { italicum } \\ \text { walls }\end{array} \\ \text { Reducing sugar (as glucose) } & 65 \cdot 4 & 72 \cdot 5 \\ \text { D-Glucose } & 45 \cdot 4 & 51 \cdot 6 \\ \text { D-Galactose } & 3 \cdot 8 & 3 \cdot 8 \\ \text { Glucosamine } & 5 \cdot 7 & 9 \cdot 0 \\ \text { Total nitrogen } & \mathrm{I} \cdot 27 & 0 \cdot 90 \\ \text { Amino sugar N (calculated) } & 0.45 & 0 \cdot 70 \\ \text { Phosphorus } & \mathrm{I} \cdot 8 & 0 \cdot 13 \\ \text { Ash } & 29 \cdot 5 & <0.5\end{array}$

Table 2. Fractionation of cell-wall material from Penicillium digitatum and P. italicum

\begin{tabular}{|c|c|c|c|c|c|}
\hline & & & & fraction & \\
\hline & $\begin{array}{c}\text { fraction } \\
(\%)\end{array}$ & $\begin{array}{l}\text { Neutral } \\
\text { sugar }\end{array}$ & Glucose & Galactose & Glucosamine \\
\hline & & & & digitatum $(\mathrm{I}$ & $\mathrm{mg}$.) \\
\hline Alkali-soluble & $22 \cdot 5$ & 88 & $6 I$ & 7 & I \\
\hline Acid-soluble & 36 & 98 & 60 & $6 \cdot I$ & $7 \cdot 5$ \\
\hline Residue & 27 & I & - & - & - \\
\hline Total recovery & 86 & & & & \\
\hline & & & & italicum $(69$ & mg.) \\
\hline Alkali-soluble & $30 \cdot 3$ & 90 & 65 & 4 & 0 \\
\hline Acid-soluble & 53 & 71 & 58 & 5 & 16.5 \\
\hline Residue & $2 \cdot 9$ & 18 & 4 & - & - \\
\hline Total recovery & 86 & & & & \\
\hline
\end{tabular}

Extraction of the cell walls of Penicillium digitatum and of $P$. italicum with ether and evaporation of the solvent from the extract gave a small amount of solid residue (about $4 \%$ of the weight of the walls), indicating a low lipid content. The cell walls were also fractioned with alkali and acid. Table 2 shows that alkali ( $\mathrm{N}$, two treatments of $3 \mathrm{hr}$ each at $23^{\circ}$ ) extracted a fraction which comprised $22 \%$ of the weight of 
$P$. digitatum walls and $30 \%$ of the walls of $P$. italicum. This fraction, composed mainly of glucose, might be a mixture of homo- or hetero-polymers.

Treatment with alkali did not affect the gross structure of the walls as seen with the electron microscope. This may indicate that the soluble polysaccharide(s) are not essential components of the rigid structure of the wall. When the fraction of the wall which was insoluble in alkali was put in $72 \%(\mathrm{v} / \mathrm{v})$ conc. $\mathrm{H}_{2} \mathrm{SO}_{4}$ in water for 2 days another portion went into solution- $36 \%$ for Penicillium digitatum and $52 \%$ for $P$. italicum. A similar figure was found by Hamilton \& Knight (1962) for walls of $P$. chrysogenum. Quantitative analysis of acid hydrolysates of this fraction revealed that it was composed mainly of glucose, with small amounts of galactose. It also contained glucosamine; it is possible that part of this glucosamine was in the form of chitin, since chitin is known to be soluble in concentrated sulphuric acid. This is in agreement with previous findings that Penicillium belongs to the group of fungi which contain chitin in their walls (Aronson, 1965). The part of the wall which was insoluble in $72 \%(\mathrm{v} / \mathrm{v})$ conc. $\mathrm{H}_{2} \mathrm{SO}_{4}$ in water did not contain any appreciable amount of carbohydrate; its amount in the case of $P$. digitatum was $27 \%$ of the walls, and this fraction may have contained the bulk of the material corresponding to the ash. Only a small amount of acid-insoluble residue was found in the walls of $P$. italicum in accord with the absence of ash from these walls.

We wish to thank the members of the Section of Biological Ultrastructure for the electron micrographs.

\section{REFERENCES}

Aronson, J. M. (1965). The cell wall. In The Fungi. Ed. by G. C. Ainsworth and A. S. Sussman, vol. I, p. 49. New York and London: Academic Press.

Boas, N. F. (1953). Method for the determination of hexosamines in tissues. J. biol. Chem. 204, 553.

CROOK, E. M. \& JoHnston, I. R. (1962). The qualitative analysis of the cell walls of selected species of fungi. Biochem. J. 83, 324.

Dubois, M., Gilles, K. A., Hamilton, J. K., Rebers, P. A. \& Smith, F. (I956). Colorimetric method for determination of sugars and related substances. Analyt. Chem. 28, 350.

GARDELL, S. (1953). Separation on Dowex 50 ion exchange resin of glucosamine and galactosamine and their quantitative determination. Acta chem. scand. 7, 207.

Hamilton, P. B. \& KNight, S. G. (1962). An analysis of the cell walls of Penicillium chrysogenum. Archs Biochem. Biophys. 99, 282.

KING, E. J. (1932). The colorimetric determination of phosphorus. Biochem. J. 26, 292.

Martin, H. H. (1966). Biochemistry of bacterial cell walls. A. Rev. Biochem. 35, 457.

Park, J. T. \& Johnson, M. J. (1949). A submicrodetermination of glucose. J. biol. Chem. 181, I49.

SHARON, N. (1965). Distribution of amino sugars in microorganisms, plants and invertebrates. In The Amino Sugars. Ed. by R. W. Jeanloz and E. A. Balazs, vol. II A, p. I. New York and London: Academic Press.

Sharon, N. \& Jeanloz, R. W. (1960). The diaminohexose component of a polysaccharide isolated from Bacillus subtilis. J. biol. Chem. 235, I.

Sharon, N. \& JeAnloz, R. W. (I964). A procedure for the preparation of gram quantities of bacterial cell walls. Experientia 20, 253.

SteYermark, A. (1961). Quantitative Organic Microanalysis, p. 177. New York and London: Academic Press.

Spackman, D. H., Stein, W. H. \& Moore, S. (1958). Automatic recording apparatus for use in the chromatography of amino acids. Analyt. Chem. 30, I190. 


\section{EXPLANATION OF PLATE}

Electron micrographs of cell walls of Penicillium digitatum hyphae.

Fig. I, magnification, $\times 5000$. Fig. 2, magnification $\times 20,000$ : note the fibrous structure of the internal part of the cell wall. 

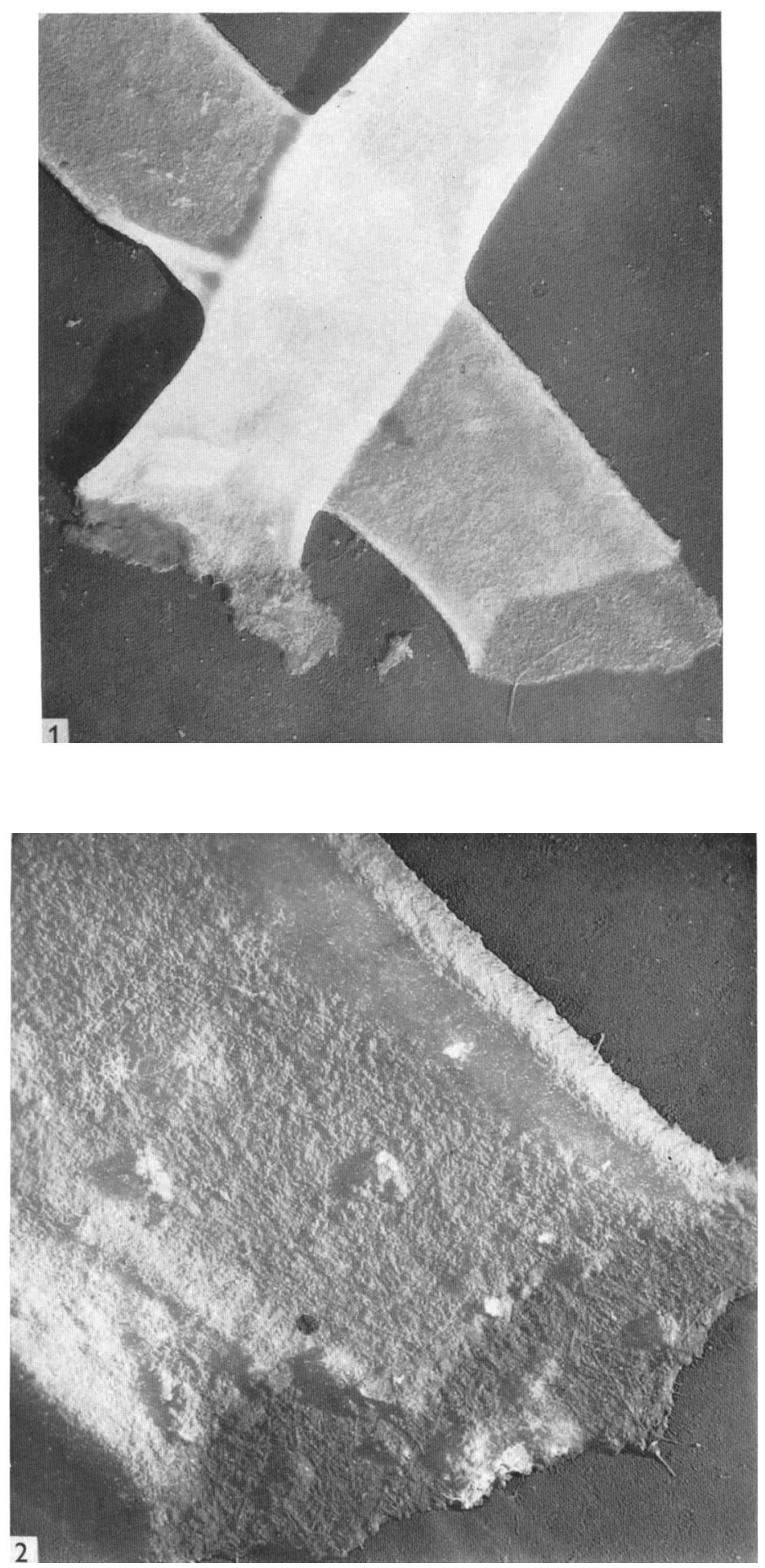